\title{
A UTILIZAÇÃO DOS INSTITUTOS JURÍDICOS DA PROPORCIONALIDADE E DA RAZOABILIDADE NO DIREITO ELEITORAL
}

\author{
The use of the institutes of proportionality and reasonableness in electoral law
}

\author{
Alex Sandro Barbosa dos Santos \\ Rogério Carlos Born
}

Resumo: Nos casos em que se deve proceder um juízo de ponderação, exige-se fundamentação detalhada com a demonstração dos critérios específicos, conforme previsão do artigo 489, \2º, da Lei 13.105, de 2015, sob pena de não se ter a adequação entre as razões de decidir e a decisão, o que prejudica a justificação e, portanto, a legitimidade do ato judicial perante os jurisdicionados e o próprio poder público. No direito eleitoral brasileiro, o legislador cria tipos abertos e fechados de normas, porquanto, quando a lei fixa uma conduta proibida em um tipo aberto, excepcionalmente permite ao magistrado a análise da conduta de forma coadunada com outros elementos num juízo de proporcionalidade e de razoabilidade. Neste caso, em relação à sanção, a lei proporciona ao julgador uma margem de escolha entre uma ou outra sanção a ser aplicada. Todavia, tal excepcionalidade deve ser fundamentada detalhadamente. Com isso, o objetivo do presente estudo é analisar, por meio do método dedutivo, a utilização dos institutos da proporcionalidade e da razoabilidade no âmbito Eleitoral, além de expor a origem, a natureza jurídica, o conteúdo e a distinção de tais institutos.

Palavras-chave: Proporcionalidade. Razoabilidade. Distinção. Aplicação. Tribunal Superior Eleitoral.

\begin{abstract}
In cases in which a weighting judgment is to be made, a detailed statement of reasons is required with the demonstration of the specific criteria, as provided for the article 489, paragraph 2, of Law 13,105, from 2015, under penalty of not having the adequation between reasons for decision and the decision, which impairs justification, and therefore the legitimacy of the judicial act, before the courts and the public authority itself. In Brazilian electoral law, the legislator creates open and closed types of norms, since when the law establishes a prohibited conduct in an open type, it exceptionally allows the magistrate to analyze the conduct in a way that is consistent with other elements in a judgment of proportionality and reasonableness , and in this case, in relation to the sanction, the law provides the judge with a margin of choice between one or another sanction to be applied. However, such exceptionality must be substantiated in detail. Therefore, the purpose of the present study is to analyze, the deductive, the use of the institutes of proportionality and reasonableness in electoral law, as well as to explain the origin, legal nature, content and distinction of such institutes, and finally, to demonstrate some decisions of the Superior Electoral Court on the subject.
\end{abstract}

Keywords: Proportionality. Reasonableness. Distinction. Application. Superior Electoral Court.

Artigo recebido em 30 maio 2019 e aprovado em 28 jun. 2019. 


\section{Introdução}

O objetivo do presente estudo é analisar, por meio do método dedutivo, a utilização dos institutos da proporcionalidade e da razoabilidade na jurisprudência do Tribunal Superior Eleitoral (TSE), além de expor a origem e o conteúdo, bem como distinguir tais institutos, e, ao final, demonstrar algumas decisões do referido colegiado acerca do tema ${ }^{1}$.

$\mathrm{Na}$ aplicação da razoabilidade e da proporcionalidade, deve-se proceder a um juízo de ponderação. E a ponderação exige fundamentação detalhada, com a demonstração dos critérios específicos, tal como exigido pelo artigo 489, \ $2^{\circ}$, do Código de Processo Civil. A correta utilização de tais institutos depende ainda da definição dos seus subelementos, sob pena de não haver a adequação entre as razões de decidir e a decisão, o que prejudica a justificação e, portanto, a legitimidade do ato judicial perante os jurisdicionados e o próprio poder público. Todavia, na análise jurisprudencial do TSE, percebe-se que tais instrumentos jurídicos são utilizados sem a necessária contextualização e de forma indistinta.

A doutrina e a jurisprudência divergem quanto à natureza dos referidos institutos, tratando-os, por vezes, como sinônimos². Assim, os institutos são qualificados como princípios, regras (Silva, 2002, p. 1), máxi-

\footnotetext{
${ }^{1}$ O presente trabalho terá como base uma análise na teoria do direito, doutrina e jurisprudência, acerca da aplicação da Proporcionalidade e da Razoabilidade envolvendo as decisões do Tribunal Superior Eleitoral. Neste caso, optou-se pelo método dedutivo. Segundo Mezzaroba e Monteiro (2016), o método dedutivo consiste em, primeiramente, apresentar os argumentos que se consideram verdadeiros e inquestionáveis para, em seguida, chegar a conclusões formais, já que essas conclusões ficam restritas única e exclusivamente à lógica das premissas estabelecidas.

${ }^{2}$ Luiz Roberto Barroso (2015) trata a proporcionalidade e a razoabilidade em tópico específico, em seu livro, como sinônimos. Gilmar Mendes (2013), ao comentar o artigo 5은 LIV, confunde as origens e a natureza jurídica da proporcionalidade e da razoabilidade. Já Suzana de Toledo Barros (2003) afirma que "o princípio da proporcionalidade, como uma construção dogmática dos alemães, corresponde a nada mais do que o princípio da razoabilidade, dos norte-americanos, desenvolvido mais de meio século antes, sob o clima de maior liberdade dos juízes na criação do direito" (p. 57-9). Na jurisprudência, não há consenso acerca da natureza jurídica da proporcionalidade e da razoabilidade, bem como se confunde o conteúdo. Assim, em que pese a utilização da preposição "e" entre os dois institutos, não é feita a devida distinção quando da sua aplicação. V.g. Brasil, 2016h, 2016b, 2018a, 2017.
} 
mas (Alexy, 2008, p. 116), postulados normativos (Ávila, 2004, p. 93-124) e método ${ }^{3}$.

A justificativa para a distinção dos institutos da proporcionalidade e da razoabilidade se encontra tanto na origem quanto no conteúdo de ambos. Enquanto aquele se consolidou em verdadeira máxima de ponderação, este representa a evolução substancial do princípio do due process of law.

Também, há dois aspectos que promovem a distinção entre tais institutos: o primeiro diz respeito à estrutura, e, o segundo, à abrangência de aplicação.

Quanto à estrutura, a proporcionalidade, nascida no direito alemão, recebeu da doutrina estrutura e distinção mais nítidas dos seus três elementos: a necessidade, a adequação e a proporcionalidade em sentido estrito. A razoabilidade, por sua vez, oriunda do sistema americano, deve ter observada os seus elementos nucleares, a saber: equidade, congruência e equivalência.

No que tange à abrangência da aplicação, a razoabilidade tem por escopo impedir atos e normas que destoem da razão, em uma relação entre meios e fins, além de permitir um certo equilíbrio equitativo, sob pena de resultar no que se chama de irrazoável. Já a proporcionalidade tem um campo bem maior de aplicação, servindo com um verdadeiro parâmetro para aferir a adequação e a oportunidade de aplicação de um determinado comando normativo.

Sendo assim, de início serão expostas a origem e a natureza jurídica da proporcionalidade e da razoabilidade, sem aprofundar neste contexto, tendo em vista as controvérsias e a amplitude para demonstrar tal caracterização. A seguir, para distinguir tais institutos, demonstrar-se-á seus principais aspectos.

\footnotetext{
${ }^{3}$ Para Jairo Gomes (2014), "a proporcionalidade não se trata propriamente de princípio, mas de método” (p. 27-33). O autor menciona ainda que princípios são considerados mandamentos de otimização e, como tal, podem ser satisfeitos ou produzir efeitos em variados graus ou medidas; a satisfação deles não depende só de circunstâncias fáticas, mas também de possibilidade jurídicas. Nesse passo, percebe-se que Gomes se utiliza da teoria de Robert Alexy, mas discorda, sob argumento de que "a proporcionalidade constitui um método fixo, em sim mesmo não comportando variações quando de sua aplicação - o que varia são os resultados que sua observância enseja". Segundo Jairo Gomes, "a proporcionalidade tem por objeto princípios colidentes, ou melhor, solucionar racionalmente a colidência”.
} 
E, ao final, em análise da forma de aplicação daqueles termos no âmbito jurisprudencial eleitoral, pretende-se demonstrar que tais institutos são, por vezes, distorcidos, principalmente a teoria alexyana, tendo em vista a ausência de fundamentação detalhada, tal como exigido pelo artigo 489, $\int 2^{\circ}$ do Código de Processo Civil.

\section{Síntese da origem e da natureza jurídica dos institutos da proporcionalidade e da razoabilidade}

As identificações históricas dos institutos aqui estudados são, por vezes, confundidas, além de serem equivocadas. Neste sentido, Silva (2002) esclarece que "a origem concreta do princípio da irrazoabilidade, na forma como aplicada na Inglaterra, não se encontra no longínquo ano de 1215, nem em nenhum outro documento legislativo posterior, mas em decisão judicial proferida em 1948” (p. 4). O referido autor também menciona que, naquela época, o teste da irrazoabilidade, conhecido também como teste Wednesbury, implicava tão somente na rejeição dos atos excepcionalmente irrazoáveis (Silva, 2002, p. 5).

A matriz jurídico-filosófica da razoabilidade é a cláusula do due process of law, que se desenvolveu a partir do direito anglo-saxônico. Sua garantia, que em um primeiro momento se restringiu a aspectos marcadamente processuais (procedural due process), evoluiu para um âmbito substantivo (substantive due process) (Mendes, 2013).

Ademais, no direito constitucional brasileiro, na disposição normativa que disciplina o devido processo legal, o artigo 5, LIV da Constituição Federal, dispõe que "ninguém será privado da liberdade ou de seus bens sem o devido processo legal” (Brasil, 1988).

A cláusula do devido processo legal é uma das mais amplas e relevantes garantias dos direitos constitucionais, levando em consideração a sua aplicação não apenas nas relações de caráter processual, mas também naquelas de caráter material (Mendes, 2013).

A proporcionalidade, por outro lado, desenvolveu-se na jurisprudência do Tribunal Constitucional alemão, no controle das leis restritivas de direitos fundamentais (Silva, 2002, p. 5).

Também, a doutrina alemã, como destaca Robert Alexy, foi responsável por esmerar referido instituto. 
Segundo Bonavides (2000), no ordenamento constitucional brasileiro, a proporcionalidade decorre "do espírito que anima em toda sua extensão e profundidade o $\$ 2^{\circ}$ do artigo $5^{\circ}$, abrange a parte não escrita ou não expressa dos direitos e garantias da Constituição" (p. 395).

\subsection{Distinção entre a proporcionalidade e a razoabilidade}

Silva (2002) afirma que é evidente que os termos, no caso, proporcionalidade e razoabilidade, "estão revestidos de uma conotação técnico-jurídica e não são mais sinônimos, pois expressam construções jurídicas diversas. Pode-se admitir que tenham objetivos semelhantes, mas isso não autoriza o tratamento de ambos como sinônimos" (p. 4).

O referido autor, além de não compartilhar com a sinonímia entre a proporcionalidade e a razoabilidade, por entender que há uma autonomia em cada uma, faz distinções entre tais institutos:

Quando se fala, em um discurso jurídico, em princípio da razoabilidade ou em princípio ou regra da proporcionalidade, é evidente que os termos estão revestidos de uma conotação técnico-jurídica e não são mais de sinônimos, pois expressam construções jurídicas diversas. Pode-se admitir que tenham objetivos semelhantes, mas isso não autoriza o tratamento de ambos como sinônimos. Ainda que se queira, por intermédio de ambos, controlar as atividades legislativa ou executiva, limitando-as para que não restrinjam mais do que o necessário os direitos dos cidadãos, esse controle é levado a cabo de forma diversa, caso seja aplicado um ou outro critério. (Silva, 2002, 4)

Dentre outros problemas, o autor supracitado também menciona a não identidade dos institutos em comento:

A exigência de razoabilidade, baseada no devido processo legal substancial, traduz-se na exigência de "compatibilidade entre o meio empregado pelo legislador e os fins visados, bem como a aferição da legitimidade dos fins". Barroso chama a primeira exigência - compatibilidade entre meio e fim - de razoabilidade interna, e a segunda legitimidade dos fins -, de razoabilidade externa. Essa configuração da regra da razoabilidade faz com que fique nítida sua não identidade com a regra da proporcionalidade. O motivo é bastante simples: o conceito de razoabilidade, na forma como exposto, corresponde apenas à primeira das três sub-regras da proporcionalidade, isto é, 
apenas à exigência de adequação. A regra da proporcionalidade é, portanto, mais ampla do que a regra da razoabilidade, pois não se esgota no exame da compatibilidade entre meios e fins. (Silva, 2002, 7)

Nesse diapasão, Streck (2016), ao diferençar a razoabilidade e a proporcionalidade, também frisa a importância da fundamentação detalhada ao aplicar os referidos institutos, e destaca que:

A razoabilidade trata da legitimidade da escolha dos fins em nome dos quais o Estado irá agir, enquanto a proporcionalidade averigua se os meios são necessários, adequados e proporcionais aos fins escolhidos. Entre outras palavras, enquanto a proporcionalidade permite observar a relação entre meio-fim inerente à medida estatal, a razoabilidade considera a relação da medida estatal (já considerada proporcional) com as situações pessoais dos indivíduos por ela afetados. Na aplicação tanto da razoabilidade como da proporcionalidade, há um juízo de ponderação. E a ponderação exige fundamentação detalhada, com a demonstração dos critérios detalhados, tal como exigido pelo artigo 489, $\$ 2^{\circ}$ do Código de Processo Civil (48-9).

Streck (2011), inclusive, faz a crítica do uso equivocado da proporcionalidade, mencionando que:

O uso descriterioso da teoria alexyana transformou a regra da ponderação em um princípio. Com efeito, se na formatação proposta por Alexy, a ponderação conduz à formação de uma regra - que será aplicada ao caso por subsunção -, os tribunais brasileiros utilizam esse conceito como se fosse um enunciado performático, uma espécie de álibi teórico capaz de fundamentar os posicionamentos mais diversos (49-50).

Destarte, há dois aspectos que promovem a distinção entre a proporcionalidade e a razoabilidade, quais sejam, a estrutura e a abrangência de aplicação.

No primeiro, a proporcionalidade, nascida no direito alemão, recebeu da doutrina uma estrutura e distinção mais nítida dos seus três elementos: necessidade, adequação e proporcionalidade em sentido estrito. $\mathrm{Na}$ razoabilidade, oriunda do sistema americano, deve ser observado os seus elementos nucleares: equidade, congruência e equivalência. 
No segundo, a razoabilidade tem por escopo impedir atos e normas que destoem da razão em uma relação entre meios e fins, além de permitir um certo equilíbrio equitativo que, como o próprio nome anuncia, seja irrazoável. Já a proporcionalidade tem um campo bem maior de aplicação, servindo com um verdadeiro parâmetro para aferir a adequação e oportunidade de escolha de um determinado comando normativo.

\section{Principais aspectos da proporcionalidade e da razoabilidade}

\subsection{Principais aspectos do instituto da proporcionalidade}

Nas lições de Alexy (2008), a proporcionalidade como máxima jurídica é constituída pelas máximas parciais, assim denominadas pelo autor, da adequação, da necessidade e da proporcionalidade em sentido estrito, as quais devem ser cumulativamente consideradas.

Então, a máxima da adequação trata de uma correspondência entre meios e fins, em que se veda a utilização de meios que venham a obstruir a realização de um princípio sem que se promova a otimização de outro. A máxima da necessidade supõe a intervenção mínima necessária para proteção do bem juridicamente protegido. E a máxima da proporcionalidade em sentido estrito preconiza que somente são válidas as restrições que obedecem à justa medida (Alexy, 2008, 583-611).

Quanto à aplicação da proporcionalidade, as três máximas parciais (adequação, necessidade e proporcionalidade, em sentido estrito) expressam ideia de otimização. As máximas de adequação e necessidade se referem à otimização no que diz respeito às possibilidades fáticas. Ponderação é o objeto da terceira máxima. Proporcionalidade, em sentido estrito, essa máxima significa a otimização no que diz respeito às possibilidades jurídicas (Alexy, 2008, 117).

Ávila faz uma importante conexão com os subprincípios da proporcionalidade e salienta que sem uma relação meio/fim, não se pode realizar o exame do postulado da proporcionalidade pela falta dos elementos estruturantes.

Relação entre meio e fim - a proporcionalidade constitui-se em um postulado normativo aplicativo, decorrente do caráter principal das normas e da função distributiva do Direito, cuja aplicação, porém, depende do imbricamento entre bens jurídicos e da existência de 
uma relação meio/fim intersubjetivamente controlável. O exame de proporcionalidade aplica-se sempre que houver uma medida concreta destinada a realizar uma finalidade. Nesse caso, devem ser analisadas as possibilidades de a medida levar à realização da finalidade (exame da adequação), de a medida ser a menos restritiva aos direitos envolvidos dentre aquelas que poderiam ter sido utilizadas para atingir a finalidade (exame da necessidade) e de a finalidade pública ser tão valorosa que justifique tamanha restrição (exame da proporcionalidade em sentido estrito). Sem uma relação meio/fim não se pode realizar o exame do postulado da proporcionalidade, pela falta dos elementos que o estruturem. Nesse sentido, importa investigar o significado de fim: fim consiste num ambicionado resultado concreto (extrajurídico); um resultado que possa ser concebido mesmo na ausência de normas jurídicas e de conceitos jurídicos, tal como obter, aumentar ou extinguir bens, alcançar determinados estados ou preencher determinadas condições, dar causa a ou impedir a realização de ações. (Ávila, 2004, 113-4)

Contudo, Silva faz uma ressalva e esclarece que a proporcionalidade não deve ser analisada somente sob o prisma da relação entre meio e fim, mas deve ser observado os seus subelementos, assim como, cumulativamente serem aplicados (Silva, 2002, 5).

\subsection{Principais aspectos do instituto da razoabilidade}

De outra face, sobre a estrutura da razoabilidade é necessário fazer uma distinção entre os seus elementos nucleares, quais sejam equidade, congruência e equivalência, os quais Ávila menciona como acepções:

Razoabilidade como equidade $-[\ldots]$ o postulado da razoabilidade exige a harmonização da norma geral com o caso individual. Em primeiro lugar, a razoabilidade impõe, na aplicação das normas jurídicas, a consideração daquilo que normalmente acontece. $[\ldots]$

Razoabilidade como congruência - [...] o postulado da razoabilidade exige a harmonização das normas com suas condições externas de aplicação. Em primeiro lugar, a razoabilidade exige, para qualquer medida, a recorrência a um suporte empírico existente.

$[\ldots]$ 
Razoabilidade como equivalência - A razoabilidade também exige uma relação de equivalência entre a medida adotada e o critério que a dimensiona. $(2004,103-9)$

O referido autor, ainda, destaca três diretrizes importantes, nas quais o instituto da razoabilidade é utilizado:

Relativamente à razoabilidade, dentre tantas acepções, três se destacam. Primeiro, a razoabilidade é utilizada como diretriz que exige a relação das normas gerais com as individualidades do caso concreto, quer mostrando sob qual perspectiva a norma deve ser aplicada, quer indicando em quais hipóteses o caso individual, em virtude de suas especificidades, deixa de se enquadrar na norma geral. Segundo, a razoabilidade é empregada como diretriz que exige uma vinculação das normas jurídicas com o mundo ao qual elas fazem referência, seja reclamando a existência de um suporte empírico e adequado a qualquer ato jurídico, seja demandando uma relação congruente entre a medida adotada e o fim que ela pretende atingir. Terceiro, a razoabilidade é utilizada como diretriz que exige a relação de equivalência entre duas grandezas (Ávila, 2004, 102).

Ademais, dentre as generalidades e pluralidades da razoabilidade, Ávila $(2004,102)$ destaca que ela "é usada com vários sentidos. Fala-se em razoabilidade de uma alegação, razoabilidade de uma interpretação, razoabilidade de uma restrição, razoabilidade do fim legal, razoabilidade da função legislativa".

Quanto à aplicabilidade da razoabilidade, há duas linhas seguidas, sendo que a primeira se restringe a aspectos marcadamente processuais (procedural due process), pois trata de direitos individuais e coletivos que atentam contra a privação de liberdade ou de seus bens sem o devido processo legal. A segunda, segue uma orientação, uma diretiva interpretativa que permite a aferição acerca da legalidade substancial dos atos administrativos e legislativos. Permite alcançar o sentido finalístico da norma, a conformidade teleológica entre o ato praticado e o mandamento normativo, numa perspectiva de legalidade material (substantive due process) (Mendes, 2013). 


\section{A utilização dos institutos jurídicos da proporcionalidade e da razoabilidade no Direito Eleitoral}

Além da origem dos institutos em comento ser diferente, assim como seus elementos/pressupostos, a doutrina os conceitua de forma distinta, e a jurisprudência do TSE apresenta dissenso quando os aplica.

Rodrigues e Jorge (2014) mencionam que, no direito eleitoral brasileiro, o legislador cria tipos abertos e fechados de normas como, por exemplo, as condutas de abuso de poder econômico e as condutas vedadas aos agentes públicos em campanha eleitoral, respectivamente.

Os autores frisam que, quando a lei fixa uma conduta proibida em um tipo aberto, permite ao magistrado a análise da conduta de forma coadunada com outros elementos num juízo de proporcionalidade e razoabilidade, e que, nesses casos, em relação à sanção, a lei proporciona ao julgador uma margem de escolha entre uma ou outra sanção a ser aplicada. Todavia, tal excepcionalidade deve ser fundamentada de forma clara e precisa, sob pena de se prolatar uma decisão não autorizada (Rodrigues e Jorge, 2014).

Neste sentido, para as condutas vedadas, tipificadas no artigo 73 e seguintes da Lei 9.504/1997, a Lei das Eleições (Brasil, 1997), as sanções descritas, também neste diploma legal, não podem ser ignoradas pelo Juízo Eleitoral. A título de exemplo, Rodrigues e Jorge (2014) citam o agravo regimental em recurso especial 30.006, de 29 de novembro de 2012, do relator ministro José Antônio Dias Tofolli, em que, com base na proporcionalidade, afasta-se a sanção de cassação prevista em lei, sob o argumento, em tese contra legem, de que a conduta, embora ocorrida, não poderia ter a sanção tipificada que o legislador previu.

Ainda sobre o artigo 73 , em seu $\int 5^{\circ}$, tratando de violação ao disposto nos incisos I, II, III, IV ou VI do caput do artigo, e sendo responsável por tal infração o candidato, então contra ele também incidirá a sanção de cassação do registro de sua candidatura ou do seu diploma, caso seja eleito. Isso porque previu o legislador que, nesses casos, a ofensa ao equilíbrio do pleito é ínsita a cada uma das condutas ali descritas.

Rodrigues e Jorge (2014) afirmam que há presunção legal no sentido de que a prática da conduta implica automática violação do equilíbrio eleitoral. Mencionam ainda que, uma vez demonstrada a prática da conduta vedada pelo candidato, a cassação do registro, ou do diploma se for eleito, será imediata. 
Por outro lado, o TSE, suavizando o texto expresso de lei com a utilização da proporcionalidade e da razoabilidade, afastou a regra da cassação imediata decorrente da prática da conduta vedada (Brasil, 2016f, 2016b, 2016a).

Pari passu, na decisão que julga procedente ação por captação (arrecadação) e gasto ilícito de recurso para fins eleitorais, disposta no artigo 30-A da Lei 9.504/97, também, segundo entendimento jurisprudencial, deve-se demonstrar a gravidade da conduta (Brasil, 2016h, 2016g).

Com isso, destaca-se o dissenso jurisprudencial quanto à aplicação dos institutos em comento, bem como para definir o que é um ato tido como grave. Assim, a sanção decorrente de tal ilicitude acarreta a não expedição de diploma ou cassação do diploma, mas, por causa do dissenso, depende da discricionariedade do julgador.

De forma semelhante, quanto ao uso indevido, desvio ou abuso do poder econômico ou do poder de autoridade, ou utilização indevida de veículos ou meios de comunicação social, em benefício de candidato ou de partido político, conforme disposição do artigo 22, XIV da Lei Complementar 64/1990 (Brasil, 1990), não se exige mais, por expressa determinação do artigo 22, XVI, que o ato abusivo tenha potencialidade lesiva em relação à possibilidade de desestabilização do pleito, mas sim em relação à gravidade das circunstâncias que o caracterizam.

Diante disso, o termo "gravidade", novamente, traz consigo um grau de discricionariedade passível de distorcer a essência dos institutos da proporcionalidade e da razoabilidade.

Ademais, para corroborar esse dissenso, Rodrigues e Jorge mencionam que a utilização dos institutos em comento para aferir se há ou não a gravidade que tipifica o abuso do poder econômico pode ser uma saída. Ressalvam, portanto, que o julgador, ao utilizar conceitos jurídicos indeterminados, precisa analisar o conjunto fático probatório e fundamentar qualquer decisão a ser tomada.

Também no que se refere às doações acima do limite legal, mais especificamente, por pessoa física, matéria disposta no artigo 23, $\int 1^{\circ}$, da Lei das Eleições, a sanção prevista pelo legislador é a de multa, a qual poderia variar entre cinco e dez vezes a quantia doada em excesso. O preciso quantum seria o máximo (dez vezes o valor doado em excesso) e o mínimo (cinco vezes o valor doado em excesso), isso antes da reforma trazida pela 
Lei 13.488, de 2017. Agora, de acordo com o $\ 3^{\circ}$ do artigo 23, incluído por esta lei, a doação de quantia acima dos limites sujeita o infrator ao pagamento de multa no valor de até $100 \%$ da quantia em excesso. Todavia, tanto antes quanto depois da redação dada pelo legislador em 2017, o critério utilizado para aplicação da multa depende dos juízos de proporcionalidade e razoabilidade, segundo o cotejo de elementos da causa como dolo, culpa etc ${ }^{4}$.

Quanto às provas obtidas por meios ilegais, a regra constitucional é a de que são "inadmissíveis, no processo, as provas obtidas por meios ilícitos" (Constituição, artigo 5, LVI), bem como existem outras limitações constitucionais ao direto à prova, como se vê nas seguintes disposições constitucionais: (i) artigo 1으. III - dignidade da pessoa humana; (ii) artigo 5º, $\mathrm{X}$ - direito à intimidade e à vida privada; (iii) artigo 5, XI - inviolabilidade do domićlio; (iv) artigo 5, XII - inviolabilidade do sigilo da correspondência e das telecomunicações.

Além disso, o artigo 157 do Código de Processo Penal regula o tratamento que se deve dar à prova ilícita, estatuindo que "são inadmissíveis, devendo ser desentranhadas do processo, as provas ilícitas, assim entendidas as obtidas em violação às normas constitucionais ou legais".

Nesse cenário, Barcelos, ao tratar das limitações à prova no processo penal, nas hipóteses da prova ilícita, menciona que a correspondente solução tem sido dada pela adoção de alguma das conhecidas teorias sobre a admissibilidade da prova obtida por meios ilícitos. São elas:

Admissibilidade processual da prova ilícita: male captum, bene retentum (mal colhido, mas bem conservado) - Nos termos dessa corrente, a prova deveria ser admitida desde que não fosse vedada por normativa de cunho processual, sem importar a relação com o direito material, ainda que constitucional. [...] E, nessa linha, vale a crítica no sentido de que essa teoria, num primeiro momento, ignora por completo o atual estágio da democracia de direito, olvidando que estamos submetidos a uma Lei Maior, que tutela direitos e garantias de todos, e que a todos vincula, inclusive o próprio Estado. [...] No Brasil, por sua vez, o entendimento pela admissibilidade processual da prova ilícita - retrógrado que é, para dizer o mínimo - não encontra guarida na majoritária jurisprudência.

Inadmissibilidade das provas ilícitas - São defensores dessa teoria os que fazem uma análise basicamente literal do disposto no inc. LVI

\footnotetext{
${ }^{4}$ V.g. Brasil, 2016e.
} 
do art. $5^{\circ}$ da Constituição Federal, ou seja, no sentido de que são inadmissíveis, no processo, as provas obtidas por meios ilícitos. [...] Os adeptos dessa teoria defendem que, a partir da previsão constitucional (art. 5, inc. LVI), o próprio Constituinte deu um caráter praticamente absoluto à vedação, proibindo, terminantemente, a utilização de provas ilícitas no âmbito do processo. [...] Ocorre que, sem prejuízo do brilhantismo dos escólios trazidos a lume, os tempos são outros e, por aí, a própria doutrina e a jurisprudência vêm atenuando, com muitas e consideráveis reservas, esse caráter absolutista da vedação, considerando que nenhum direito constitucional é absoluto diante de seu convívio com outros.

Admissibilidade da prova ilícita à luz do princípio da proporcionalidade ou da razoabilidade - Os defensores dessa corrente, em grande parte (alguns desavisados), defendem que, em determinados casos, tendo em vista a relevância de um suposto interesse público a ser preservado, poderia ser admitida a prova mesmo que ilícita. O entendimento em questão abranda a proibição (CF, art. 5, inc. LVI) para admitir a prova ilícita em casos excepcionais e graves, quando a obtenção e a admissão forem consideradas a única forma possível e razoável de proteger os outros valores fundamentais.

Admissibilidade da prova ilícita a partir da proporcionalidade pro reo - Nesse caso, a prova ilícita poderia ser admitida e valorada apenas quando se revelasse a favor do réu, como a própria nomenclatura sugere. (Barcelos, 2014, 38-50)

O referido autor esclarece, ainda, que, no processo penal eleitoral, é pernicioso o uso de conceitos vagos e subjetivos para viabilizar a inserção no processo de provas ilícitas, e frisa que:

Em muitos provimentos jurisdicionais, e ainda, em ensinamentos doutrinários, juristas vêm expressando construções intelectuais que ainda laboram no reducionista critério interesse público privado, tudo com vistas, a partir de um pretenso "juízo de proporcionalidade" ou "ponderação", dar "ares de legalidade" a vilipêndio de direitos fundamentais, em prol de um indeterminado, discricionário e manipulável "bem maior". [...] Em matéria eleitoral, ademais, vale frisar que todos os interesses em xeque, incluindo-se aí os dos acusados, superam em abismo a órbita do privado, restando inseridos, de igual sorte, no cenário dos direitos fundamentais, no público, portanto, se assim desejarem, não se afigurando, pois, como pertinentes, os discursos reducionistas e discricionários da ordem dos que aqui se combatem. (Barcelos, 2017, 22-3) 
Barcelos então critica o entendimento apresentado nos autos do Recurso Eleitoral 13.653-50, originário do Tribunal Regional Eleitoral da Bahia, o qual entendeu que a prova, ainda que considerada ilícita, foi analisada em virtude do princípio da ponderação de interesse (proporcionalidade), e assim questiona:

Certo?

Errado, e muito!

O Direito não deve ser realizado a qualquer preço, afinal, importa recordar que, aqui, o meio ainda continua justificando o fim, ao passo que dar guarida, no processo, a elementos probatórios obtidos por meios ilícitos, por intermédio de argumentos indeterminados e rançosos como o que aqui se combate ("prevalência" ou "supremacia" do interesse público), não encontra lastro no regime democrático de direito.

A manipulação que se promove, a partir do momento em que se eleva um vago e subjetivo interesse público, com fins de admitir uma prova, ainda que manifestamente ilícita, é algo gravíssimo e diretamente atentatório a ordem constitucional. [...]

A própria teoria da proporcionalidade ou da razoabilidade não se presta a isso (!), sendo mister reforçar a crítica à (conveniente) discricionariedade envolta à aplicação desta, ainda mais quando a temática vem a envolver controvérsias que recaem sobre as provas ilícitas. (Barcelos, 2017, 22-3)

Tal entendimento, relativo à admissibilidade da prova ilícita, ganhou maior notoriedade em primeiro de março de 2016, durante o julgamento do Habeas Corpus 308-08 (Brasil, 2016c) e do 444-05 (Brasil, 2016d), ambos de relatoria da ministra Maria Thereza de Assis Moura. Outrossim, desde 16 de abril de 2015, no Recurso Especial Eleitoral 63.761 (Brasil, 2015), o TSE iniciou mudança de posicionamento no julgamento e assentou que a gravação ambiental, sem a autorização judicial, é lícita quando realizada em ambientes públicos, admitindo-a como meio de prova contra a parte em processo cível-eleitoral. Decidiu-se que: (i) as gravações ambientais efetuadas em espaços/meios públicos não precisam ser antecedidas de decisão judicial autorizadora; e (ii) as gravações ambientes empreendidas em ambiente privado, para serem admissíveis no processo, dependem do requisito da autorização judicial prévia. 
Nesse caminho, o TSE também segue uma linha tênue no que tange à admissibilidade de metadados como prova lícita, sob o argumento da não violação da privacidade à luz da proporcionalidade com base na interpretação sistemática, e à luz de precedentes do Supremo Tribunal Federal e do Superior Tribunal de Justiça (RHC 51.531/RO). Aquele colegiado superior entendeu que:

O postulado (sic) da proporcionalidade, vetor cardeal da Constituição pós-positivista de 1988, aponta no sentido da licitude do aproveitamento de provas decorrentes da obtenção de metadados (registros de informações) em mídias sociais (e.g., Whatsapp, Facebook etc.), ainda que sem autorização judicial, sem que isso conflagre violação ao direito fundamental à privacidade (CRFB/88, art. 5ำ X). (Brasil, 2018b)

Em concomitância, no que tange à propaganda na internet com a comunicação de massa, o direito eleitoral tentou conciliar-se com o Marco Civil da Internet através da minirreforma promovida pela Lei 13.488/2017, que alterou a Lei das Eleições. Estabeleceu-se que a suspensão da propaganda na internet deve ser definida proporcionalmente à gravidade da infração cometida, conforme previsão do artigo 57-I da referida lei. Porquanto, inclusive anterior às mudanças da minirreforma, os julgadores eleitorais estabeleciam que a suspensão da propaganda devia ser definida proporcionalmente à gravidade da infração cometida. Com isso, proferiam decisões utilizando-se dos institutos da proporcionalidade e da razoabilidade no caso de descumprimento de ordem judicial para remoção da página que veiculava tal propaganda tida como irregular ${ }^{5}$.

\section{Considerações finais}

Foi abordado o uso indistinto dos institutos da proporcionalidade e da razoabilidade pela jurisprudência do Tribunal Superior Eleitoral. Partiu-se da exposição de origem, natureza jurídica e conteúdo. Com isso, ao analisar algumas decisões do referido colegiado, ficou evidente o dissenso na aplicação dos institutos, após expor os elementos e distingui-los.

Observou-se a distinção tanto na origem quanto no conteúdo de ambas. Assim, a proporcionalidade, nascida no direito alemão, recebeu da

\footnotetext{
${ }^{5}$ Sobre a suspensão da propaganda na internet e o bloqueio de aplicações de internet, cf. Rais, 2018.
} 
doutrina uma estrutura com seus três elementos (necessidade, adequação e proporcionalidade, em sentido estrito). Por sua vez, a razoabilidade, oriunda do sistema americano, possui seus elementos nucleares (equidade, congruência e equivalência).

No decorrer do trabalho, evidenciou-se que, no direito eleitoral brasileiro, quando a lei fixa uma conduta proibida em um tipo aberto, permite ao magistrado a análise da conduta de forma coadunada com outros elementos, em juízos de proporcionalidade e de razoabilidade. Nesses casos, excepcionalmente em relação à sanção, a lei proporciona ao julgador uma margem de escolha entre uma ou outra sanção a ser aplicada. Todavia tal excepcionalidade deve ser fundamentada de forma clara e precisa, sob pena de prolatar-se uma decisão não autorizada.

Desta forma, em análise jurisprudencial do TSE, evidenciou-se que a proporcionalidade e a razoabilidade são aplicadas de maneira generalizada na fundamentação das decisões do colegiado. Principalmente se utilizando do termo "grave" ou "gravidade" para suavizar, com base na proporcionalidade e na razoabilidade, a sanção de cada tipo.

Assim, tendo em vista pressupostos, critérios e elementos diversos, bem como não feita qualquer distinção ao aplicar os institutos da proporcionalidade e da razoabilidade, conclui-se que se tem uma decisão a qual não preencheu os elementos exigidos pelo artigo 489, \ $2^{\circ}$ do Código de Processo Civil.

Consequentemente, como menciona Streck (2011) ao citar uso equivocado da teoria alexyana, "os tribunais brasileiros utilizam tal conceito como se fosse um enunciado performático, uma espécie de álibi teórico capaz de fundamentar os posicionamentos mais diversos” (p. 49-50).

\section{Referências}

ALEXY, R. Teoria dos Direitos Fundamentais. Tradução Luís Virgílio Afonso da Silva. São Paulo: Malheiros, 2008.

ÁVILA, H. Teoria dos princípios: da definição à aplicação dos princípios jurídicos. 4. ed. São Paulo: Malheiros, 2004.

BARCELOS, G. R. C. Processo judicial eleitoral \& provas ilícitas: a problemática das gravações ambientais clandestinas. Curitiba: Juruá, 2014. 
. (2017). Das gravações ambientais clandestinas à construção de ilícitos de ensaio: processo judicial eleitoral e provas ilícitas. Disponível em: https://bit.ly/2VqfnXf. Acesso em: 10 out. 2018.

BARROS, S. T. de. O princípio da proporcionalidade e o controle de constitucionalidade das leis restritivas de direitos fundamentais. 3. ed. Brasília, DF: Brasília Jurídica, 2003.

BARroso, L. R. Curso de Direito Constitucional Contemporâneo. 5. ed. São Paulo: Saraiva, 2015.

BONAVIDES, P. Curso de Direito Constitucional. 10. ed. São Paulo: Malheiros, 2000.

BRASIL. Decreto-lei no 3.689, de 03 de outubro de 1941. Código de Processo Penal. Brasília, DF: Senado Federal, 1941.

Constituição Federal. Constituição da República Federativa do Brasil de 1988. Brasília, DF: Senado Federal, 1988.

. Lei Complementar no 64, de 18 de maio de 1990. Estabelece, de acordo com o art. 14, \9º da Constituição Federal, casos de inelegibilidade, prazos de cessação, e determina outras providências. Brasília, DF: Senado Federal, 1990.

. Lei no 9.504, de 1997. Estabelece normas para as eleições. Brasília, DF: Senado Federal, 1997.

. Lei no 13.105, de 16 de março de 2015. Código de Processo Civil. Brasília, DF: Senado Federal (2015).

BRASIL. (2015). Tribunal Superior Eleitoral. Recurso Especial Eleitoral no 63761. Acórdão, Relator Min. Henrique Neves Da Silva. Diário de Justiça: tomo 95, p. 65-66, Brasília, DF, 21 maio 2015.

. (2016a). Tribunal Superior Eleitoral. Recurso Ordinário no 6453. Acórdão, Relatora Min. Maria Thereza Rocha de Assis Moura. Diário de Justiça: Brasília, DF, 1 mar. 2016.

. (2016b). Tribunal Superior Eleitoral. Recurso Especial Eleitoral no 30298. Acórdão, Relator Min. Luiz Fux. Diário de Justiça: Brasília, DF, 17 mar. 2016.

. (2016c). Tribunal Superior Eleitoral. Habeas Corpus n⿳ํㅡㄴ 30808.

Relatora Min(a). Maria Thereza Rocha de Assis Moura. Diário de Justiça: Brasília, DF, 28 abr. 2016. 
. (2016d). Tribunal Superior Eleitoral. Habeas Corpus no 44405. Relatora Min(a). Maria Thereza Rocha de Assis Moura. Diário de Justiça: tomo 86, Brasília, DF, 5 maio 2016.

. (2016e). Tribunal Superior Eleitoral. Agravo de Instrumento oํ 991. Acórdão, Relator Min. Henrique Neves Da Silva. Diário de Justiça: tomo 121, p. 62-63, Brasília, DF, 24 jun. 2016.

- (2016f). Tribunal Superior Eleitoral. Recurso Ordinário no 198403. Acórdão, Relatora Min. Luciana Christina Guimarães Lóssio. Diário de Justiça: p. 33, Brasília, DF, 12 set. 2016.

. (2016g). Tribunal Superior Eleitoral. Recurso Especial Eleitoral no 204, Acórdão, Relator(a) Min. Luiz Fux. Diário de Justiça: tomo 191, p. 141 142, Brasília, DF, 4 out. 2016.

. (2016h). Tribunal Superior Eleitoral. Recurso Especial Eleitoral $n^{\circ}$ 191. Acórdão, Relator Min. Luiz Fux. Diário de Justiça: tomo 229, p. 28-29, Brasília, DF, 19 dez. 2016.

. (2017). Tribunal Superior Eleitoral. Recurso Especial Eleitoral no 10705. Acórdão, Relator(a) Min. Gilmar Mendes. Diário de Justiça: Brasília, DF, 2 fev. 2017.

. (2018a). Tribunal Superior Eleitoral. Agravo de Instrumento $\mathrm{n}^{\mathrm{a}}$ 21054. Acórdão, Relator(a) Min. Luiz Fux. Diário de Justiça: Brasília, DF, 22 mar. 2018.

. (2018b). Tribunal Superior Eleitoral. Recurso Ordinário ํํำ 122086.

Acórdão, Relatora Min. Luciana Lóssio. Diário de Justiça: tomo 61, p. 2-7, Brasília, DF, 27 mar. 2018.

CANOTILHO, J. J. G. Direito constitucional e teoria da constituição. 6. ed. Coimbra: Almedina, 2002.

CANOTILHO, J. J. G. et al. (coords). Comentários à Constituição do Brasil. São Paulo: Saraiva, 2013.

GOMES, J. J. Direito eleitoral. 10. ed. São Paulo: Atlas, 2014.

MENDES, G. F. (2013). Comentários ao artigo 5º, LIV. In: CANOTI-

LHO, J. J. G. et al. (coords.). Comentários à Constituição do Brasil. São Paulo: Saraiva. p. 427-432, 2013. 
MEZZAROBA, O.; MONTEIRO, C. S. Manual de metodologia de pesquisa no Direito. 7. ed. São Paulo: Saraiva, 2016.

RAIS, D. (coord.). Direito eleitoral digital. São Paulo: Revista dos Tribunais, 2018.

RODRIGUES, M. A.; JORGE, F. C. Manual de Direito Eleitoral. São Paulo: Revista dos Tribunais, 2016.

SILVA, L. V. A. da. O proporcional e o razoável. Revista dos Tribunais, São Paulo, vol. 91, n. 798, p. 23-50, 2002.

STRECK, L. L. et al. (orgs.). Comentários ao Código de Processo Civil. São Paulo: Saraiva, 2016.

Verdade e consenso: constituição, hermenêutica e teorias discursivas. 4. ed. São Paulo: Saraiva, 2011.

Alex Sandro Barbosa dos Santos - Graduado em Direito no Centro Universitário Dom Bosco (UniDomBosco). E-mail: a.sandrobarbosa@gmail.com.

Rogério Carlos Born - Mestre e doutorando em Direito Constitucional na linha de Direitos Fundamentais e Democracia. Professor universitário do UniDomBosco e do Centro Universitário Internacional (Uninter). Membro da Comissão de Direito Internacional da Ordem dos Advogados do Brasil do Paraná (OAB-PR). Servidor da Justiça Eleitoral e editor da revista Paraná Eleitoral. Autor de diversas obras, palestrante e conferencista. E-mail: rcborn@uol.com.br. 
